\title{
GMR
}

\section{Molecular cloning, sequencing, and expression of Eimeria tenella HSP70 partial gene}

\author{
A.L.G. Bogado, G.F. Martins, J.P. Sasse, J. da S. Guimarães Jr. and \\ J.L. Garcia \\ Laboratório de Protozoologia, Departamento de Medicina Veterinária Preventiva, \\ Universidade Estadual de Londrina, Londrina, PR, Brasil \\ Corresponding author: J.L. Garcia \\ E-mail: joaoluisgarcia10@gmail.com
}

Genet. Mol. Res. 16 (1): gmr16018964

Received July 13, 2016

Accepted February 20, 2017

Published March 15, 2017

DOI http://dx.doi.org/10.4238/gmr16018964

Copyright (C) 2017 The Authors. This is an open-access article distributed under the terms of the Creative Commons Attribution ShareAlike (CC BY-SA) 4.0 License.

\begin{abstract}
Members of the Eimeria genus are protozoan parasites of the subphylum Apicomplexa (Eimeriidae family), and belong to the coccidia group. Eimeria tenella is one of the most pathogenic species owing to its ability to penetrate the mucosa, and cause inflammation and damage. It is an obligate intracellular parasite that causes disease by destroying the host cells during multiplication. Heat shock protein 70 (HSP70) is a molecular chaperone that prevents cellular stress. The objective of this study was to clone, sequence, and express E. tenella HSP70 protein. After selecting the region of highest hydrophilicity in the $h s p 70$ gene, we cloned complementary DNA (cDNA) into a pTrcHis2-TOPO vector and transformed it into TOP10 Escherichia coli cells; after induction, the bacteria expressed a $23-\mathrm{kDa}$ protein with insoluble expression levels of approximately $5 \mathrm{mg} / \mathrm{L}$. In summary, the partial $h s p 70$ gene was successfully expressed in E. coli, producing a 23-kDa protein under insoluble conditions, and the antigen characteristics predicted by hydrophilicity analysis suggest the development of a vaccine for use in avian coccidiosis.
\end{abstract}

Key words: Coccidiosis; Eimeriosis; Molecular biology; Cloning; pTrcHis2-TOPO; Hydropathy analysis 


\section{INTRODUCTION}

Avian coccidiosis is caused by protozoan parasites of the genus Eimeria, which cause economic global losses of more than three billion dollars per year in the poultry industry (Shirley et al., 2004; Zhang et al., 2012). Control of poultry coccidiosis is based on the use of prophylactic coccidiostat drugs. However, new means of control are necessary owing to the emergence of resistance to anticoccidial products and the regulation of these drugs in the production of broiler chickens (Williams, 2002; Jang et al., 2011).

Recombinant protein vaccines derived from Eimeria spp may induce protective immunity against coccidiosis from a specific antigen, especially if associated with adjuvants (Lillehoj et al., 2005; Jang et al., 2011), presenting great potential for their use as an alternative to anticoccidial agents.

Many antigens - such as organelles from the apical complex (micronemes, rhoptries, and dense granules), structural elements (conoid, polar, and microtubules ring), and membrane proteins (Ma et al., 2011) - have been studied because they have the potential to interact with the host's immune system. Reviews by Ahmad et al. (2016) and Meunier et al. (2016) describe several types of antigens that have been evaluated as subunit vaccines against avian coccidiosis. In this context, heat shock protein 70 (HSP70) has emerged as an immunostimulatory component for the development of subunit vaccines (Zhang et al., 2012). A comparison of heat shock proteins from different organisms, from bacteria to humans, has identified highly conserved domains (Del Cacho et al., 2008). The role of these proteins is to promote the maintenance of homeostasis and cellular functions through protection from the deleterious effects caused by cellular stress from both the host and the environment (Del Cacho et al., 2008; Zhang et al., 2012).

The purpose of this study was to clone the regions of greatest hydrophilicity in HSP70 from Eimeria tenella and express them in Escherichia coli.

\section{MATERIAL AND METHODS}

\section{Eimeria tenella strain}

Eimeria oocysts were multiplied in day-old, coccidian-free Cobb broiler chicks housed in wire cages; food and water were supplied ad libitum. The experiment received ethics approval according the norms of the Ethics Committee on Animal Experimentation of Universidade Estadual de Londrina (ECAE/UEL No. 96/09). E. tenella sporozoites were purified according to the method described by Garcia et al. (2008). Briefly, the oocysts were sterilized with sodium hypochlorite and sporulated in $2.5 \%$ potassium dichromate. After sporulation, the oocysts were washed with phosphate-buffered saline (PBS; $\mathrm{pH} 7.5$ ) to remove potassium dichromate, and the sporulated oocyst walls were disrupted by shaking with sterile $3-\mathrm{mm}$ glass beads in a vortex for $5 \mathrm{~min}$. The obtained sporocysts were resuspended in $50-\mathrm{mL}$ tubes containing $0.25 \%$ trypsin $(\mathrm{v} / \mathrm{v})$ (SigmaAldrich, St. Louis, MO, USA) and 4\% taurodeoxycholate acid (w/v) (Sigma-Aldrich, St. Louis, MO) in PBS, and placed in a shaking water bath at $41^{\circ} \mathrm{C}$ for $45 \mathrm{~min}$. Subsequently, the excystated sporozoites were centrifuged at $700 \mathrm{~g}$ for $20 \mathrm{~min}$ at room temperature, and washed three times with PBS. The suspension was adjusted to a concentration of $10^{7}$ sporozoites $/ \mathrm{mL}$.

Genetics and Molecular Research 16 (1): gmr16018964 


\section{Primer design and antigenic peptide prediction}

Specific primers were designed based on the hsp70 gene from sequence Z46965.1 deposited in GenBank using online software Primer3Plus (http://www.bioinformatics.nl/ cgi-bin/primer3plus/primer3plus.cgi). The primer sequences were as follows: hsp70-F (5'-GAGAAAGAAGACGGACGCAC-3') and $h s p 70-\mathrm{R}$ (5'-CTGATACACCTTGATGCCCAC $\left.-3^{\prime}\right)$. The selected region met two criteria: correspondence with an open reading frame (ORF) to obtain the coding sequence (CDS); and potential hydrophilic regions of the protein identified using the Kyte and Doolittle (1982) algorithm (http://web.expasy.org/ProtScale).

\section{$h s p 70$ cDNA and construction of cloning vector pTrcHis2-TOPO- $h s p 70$ gene}

The total RNA was isolated from sporozoites using TRIzol ${ }^{\circledR}$ (Invitrogen, Carlsbad, CA, USA) according to the manufacturer instructions. The cDNA sequence encoding E. tenella HSP70 was obtained by reverse transcription of $1 \mathrm{mg}$ of the total RNA using a ProtoScript ${ }^{\circledR}$ M-MuLV kit (New England Biolabs, Beverly, MA, USA). The polymerase chain reaction (PCR) was carried out in a total volume $(25 \mu \mathrm{L})$ containing 50 ng E. tenella hsp $70 \mathrm{cDNA}$ template, $1 \mu \mathrm{L}$ each of the primers at 20 pmol, $200 \mu \mathrm{M}$ each deoxynucleoside triphosphate, $0.5 \mu \mathrm{L} 50 \mathrm{mM}$ magnesium sulfate, and $1 \mathrm{U}$ Platinum Taq DNA polymerase (Invitrogen, Carlsbad, CA, USA). PCR was carried out by denaturing the DNA at $94^{\circ} \mathrm{C}$ for $5 \mathrm{~min}$, followed by amplification for 35 cycles, secondary denaturation at $94^{\circ} \mathrm{C}$ for $1 \mathrm{~min}$, annealing at $60^{\circ} \mathrm{C}$ for $45 \mathrm{~s}$, and extension at $72^{\circ} \mathrm{C}$ for $1 \mathrm{~min}$, with a final extension at $72^{\circ} \mathrm{C}$ for $15 \mathrm{~min}$. The PCR product was analyzed by electrophoresis on $1.5 \%$ agarose gel stained with SYBR Green (Invitrogen), and the gel image was documented. A 100-bp size ladder (New England BioLabs Inc., Beverly, MA, USA), was used as a marker to indicate the sizes of the amplicons. The fragments containing $h s p 70$ were purified using an QIAquick Gel Extraction kit (Qiagen Biotechnology Brazil, Ltd., São Paulo, SP, Brazil), ligated into vector pTrcHis2-TOPO ${ }^{\circledR}$ (Invitrogen), and transformed into chemically competent TOP10 One-Shot E. coli cells (Invitrogen) according to the manual instructions.

\section{Sequencing and alignment}

Insertion of the correct sequence into the expression vector was confirmed by sequencing the plasmid. Briefly, after identifying the colony that expressed the protein, PCR was carried out with the specific primers provide by the pTrcHis2-TOPO kit (Invitrogen), following the manual instructions. In sequence, the DNA was purified from agarose gel using a QIAquick Gel Extraction Kit (Qiagen Biotechnology Brazil Ltd.). Sequencing reactions were performed using a fluorescent dye-labeled dideoxynucleotide system (BigDye Terminator V3.1 Cycle Sequencing Kit; Applied Biosystems, Foster City, CA, USA) with the same primers mentioned above in pTrcHis2-TOPO to confirm the maintenance of the hsp 70 ORF, as described by Igarashi et al. (2010), prior to carrying out protein expression on a larger scale. After careful examination of each electropherogram, the consensus sequences were constructed from alignment data using ClustalX (Thompson et al., 1997) and edited by visual inspection using the BioEdit program.

Genetics and Molecular Research 16 (1): gmr16018964 


\section{Identification of expression by the recombinant plasmid and protein purification}

We initially carried out a protein expression pilot as a preliminary study to identify HSP70-expressing colonies by inoculating a single colony into test tubes containing LuriaBertani (LB) broth culture medium $(3 \mathrm{~mL})$. Once the colonies had been identified, they were cultured in larger volumes of LB medium.

The protein was expressed in E. coli strain TOP10 One shot ${ }^{\circledR}$ (Invitrogen). Briefly, cells were grown in LB broth culture with $100 \mu \mathrm{g} / \mathrm{mL}$ ampicillin at $37^{\circ} \mathrm{C}$ to an optical density at wavelength $600 \mathrm{~nm}\left(\mathrm{OD}_{600}\right)$ of $0.5-0.7$, measured on an iMark ${ }^{\mathrm{TM}}$ Absorbance Microplate Reader spectrophotometer (Bio-Rad, Hercules, CA, USA). rHSP70 protein expression was induced in LB medium containing $1 \mathrm{mM}$ isopropyl-thio-D-galactoside for $4 \mathrm{~h}$ at $37^{\circ} \mathrm{C}$, agitated at $200 \mathrm{rpm}$. The HSP70 protein was purified by Ni-NTA nickel resin affinity chromatography (Qiagen Biotechnology Brazil Ltd.) under denaturing conditions, according to the manual instructions, whereby guanidine was used to lyse and bind the proteins in the resin and 8 $\mathrm{M}$ urea was used for washing and elution. The final purified solution was dialyzed in PBS and subjected to $12 \%$ polyacrylamide gel electrophoresis. The protein concentration was determined using a Pierce ${ }^{\circledR}$ BCA Protein Assay Kit (Thermo Scientific, San Jose, CA, USA).

\section{Grand average of hydropathy (GRAVY) analysis of rHSP70 protein}

The GRAVY index is the sum of the amino acid hydropathy values divided by the number of residues in the sequence, normalized according to the protein length; hydrophobic proteins have positive GRAVY values and hydrophilic proteins have negative values (Kyte and Doolittle, 1982). This index was calculated using free software available at ExPASy server (http://web.expasy.org/cgi-bin/protscale/protscale.pl).

\section{RESULTS}

\section{Molecular characterization of the partial sequence of rHSP70}

Figure 1 is a hydropathic index plot of the predicted partial amino acid sequence encoded by the $h s p 70$ gene obtained by the Kyte and Doolittle method. The observed GRAVY value was -0.089 . The primers selected to cover that area were able to amplify the 768-bp fragments from the cDNA and plasmid (pTrcHis2/HSP70), as shown in Figure 2. The new cDNA sequence obtained in this study was deposited in GenBank (accession No: KT347312); the sequence had $100 \%$ identity with the unique E. tenella HSP70 sequence in GenBank (Figure 3).

\section{Expression and purification of rHSP70}

The inclusion of a C-terminal polyhistidine-tag on the HSP70 fragment resulted in a total of 289 amino acids with a theoretical molecular mass of $31.34 \mathrm{kDa}$, and a dominant protein band at approximately $23 \mathrm{kDa}$ was observed by sodium dodecyl sulfate polyacrylamide gel electrophoresis (SDS-PAGE) (12\% polyacrylamide gel) when the insoluble fraction was analyzed (Figure 4). The expression level of this recombinant protein in E. coli One Shot ${ }^{\mathbb{E}}$ TOP10 cells (Invitrogen) was approximately $5.0 \mathrm{mg} / \mathrm{L}$.

Genetics and Molecular Research 16 (1): gmr16018964 


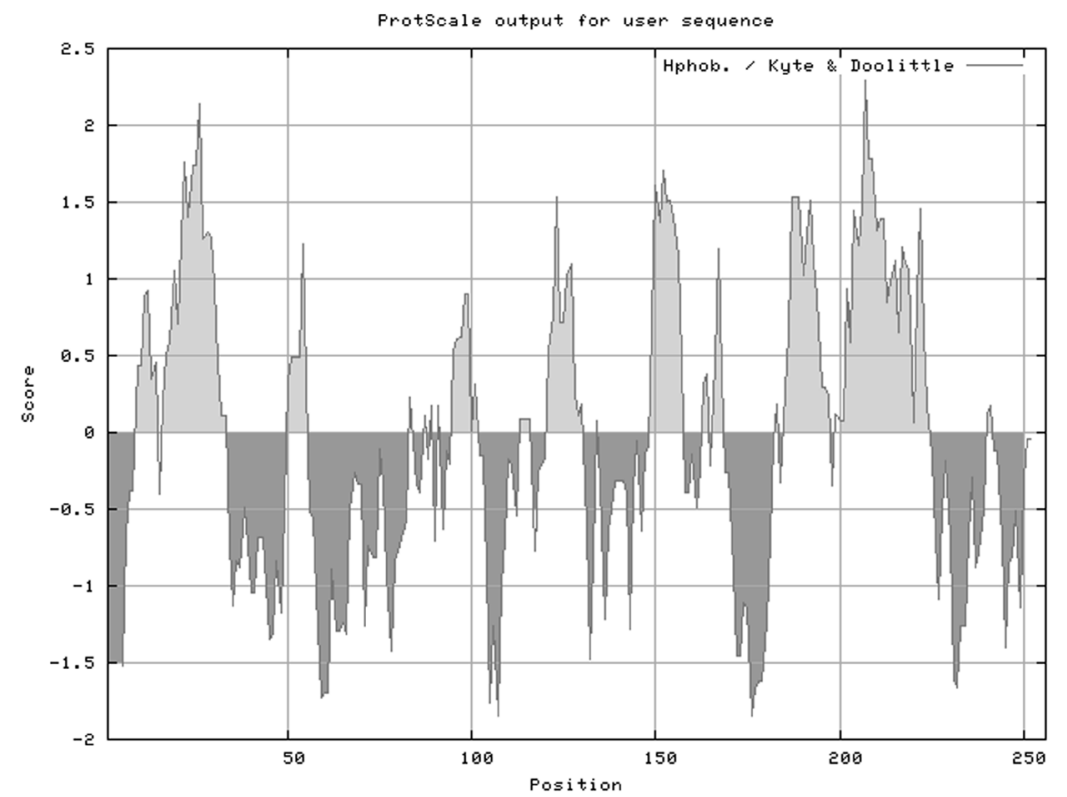

Figure 1. Hydropathic index plot of the partial amino acids sequence of the $h s p 70$ gene obtained by the Kyte and Doolittle method. The $\mathrm{x}$-axis represents the amino acid position and the $\mathrm{y}$-axis represents the hydropathic score. Hydrophobic amino acids have scores above zero (light gray areas) and hydrophilic amino acids have scores below zero (dark gray areas). The grand average of hydropathy (GRAVY) value of the rHSP70 protein was -0.089 .

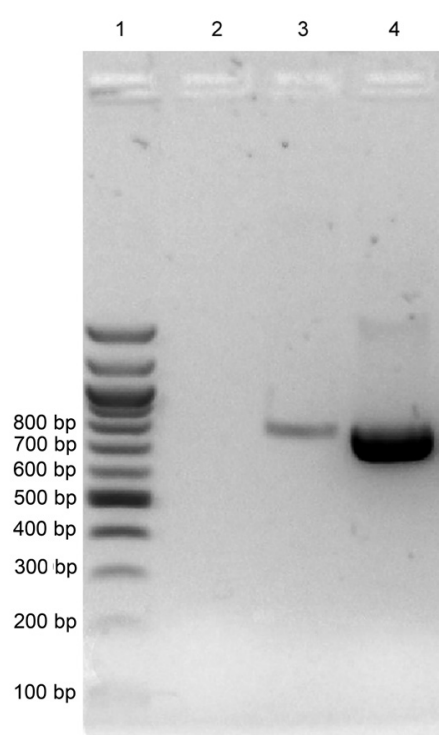

Figure 2. Amplified polymerase chain reaction (PCR) products. Lane 1: molecular weight standard $100 \mathrm{pb}$ (NEB, New England); lane 2: negative control; lane 3: cDNA amplicon; and lane 4: plasmid pTrc2His/HSP70 amplicon from the bacterial colony that expressed the rHSP70 protein. After carrying out PCR with the HSP70-F and -R primers, all samples were subjected to electrophoresis on $1.5 \%$ agarose gel and stained with SYBR Green ${ }^{\circledR}$. The presence of the insert was confirmed using $h s p 70$ primers for cDNA and the pTrc2His/HSP70 plasmid resulting in a 768-pb fragment.

Genetics and Molecular Research 16 (1): gmr16018964 


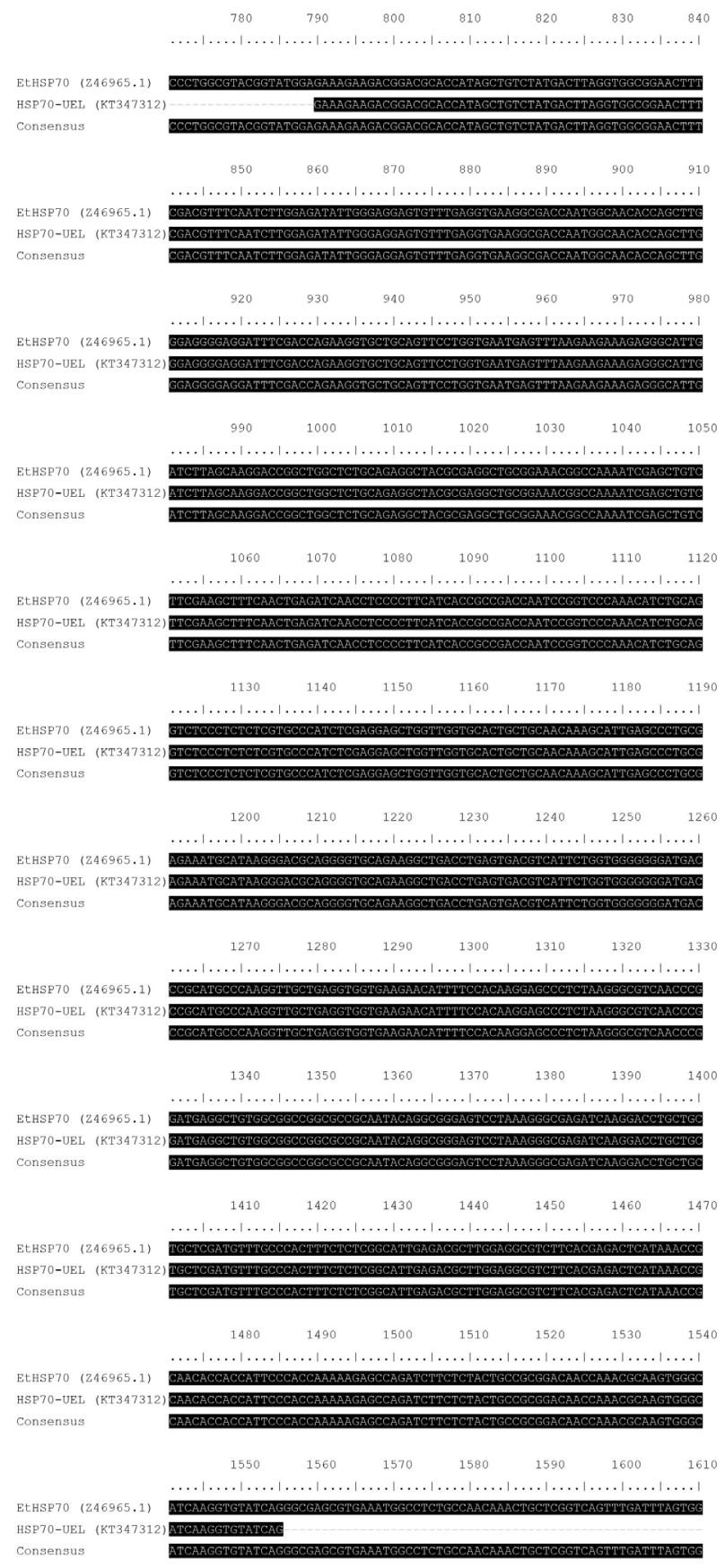

Figure 3. Alignment of the hsp 70 gene. EtHSP70 (Z46965.1): sequence deposited in GenBank (accession number Z46965.1). HSP70-UEL (KT347312): sequencing of the cloned cDNA fragment. Consensus: consensus sequences of EtHSP70 (Z46965.1) and HSP70-UEL (KT347312). The sequence alignment revealed 100\% nucleotide identity.

Genetics and Molecular Research 16 (1): gmr16018964 


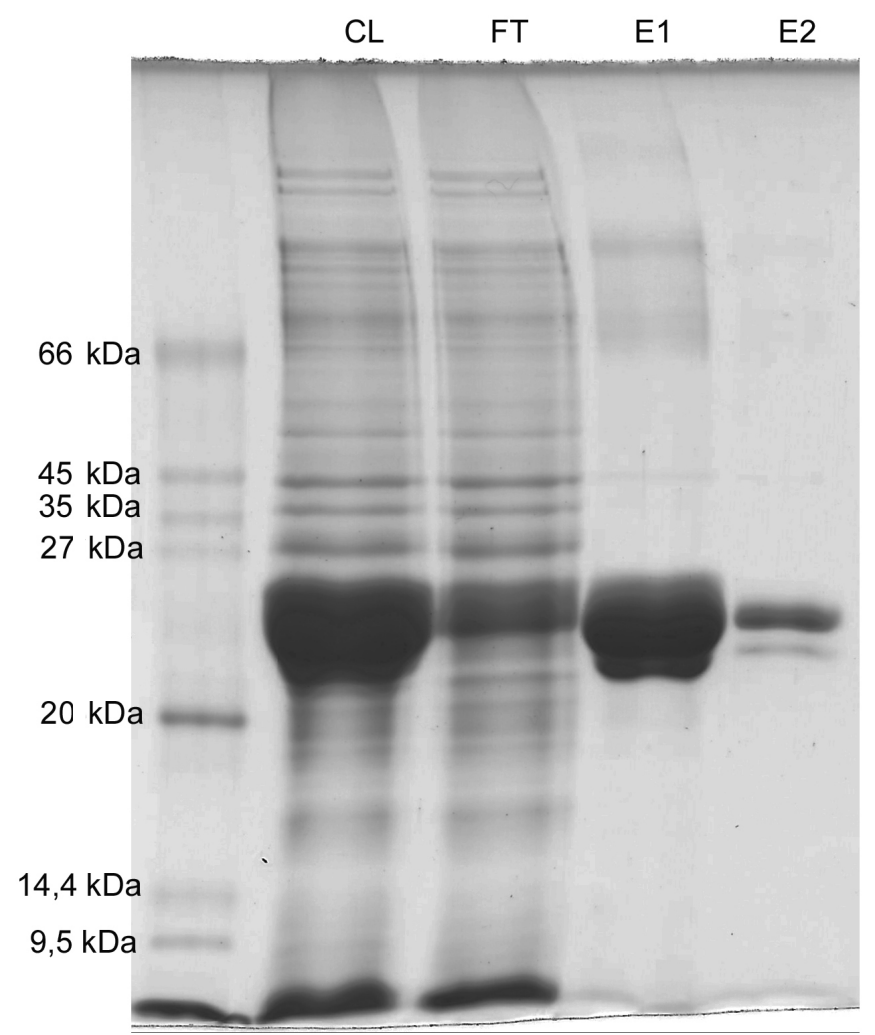

Figure 4. Expression and purification of recombinant protein HSP70. Purified insoluble proteins were subjected to sodium dodecyl sulfate polyacrylamide gel electrophoresis (SDS-PAGE) (polyacrylamide gel 12\%) and stained with Coomassie Brilliant Blue. Lane 1: molecular weight; lane 2: crude bacterial lysate; lane 3: Ni-NTA column flow-through; lane 4: first elution; and lane 5: second elution.

\section{DISCUSSION}

The rHSP70 obtained in the present work had a negative GRAVY value, indicating a hydrophilic tendency. This condition is important for immunogenicity, and may indicate potential for vaccine development (Mohamed et al., 2003; Zhang et al., 2012) because it facilitates the increased production of IL-12, IL-17, and IFN- $\gamma$ (Zhang et al., 2012). These cytokines are associated with a strong Th1 response, which is the main immune response against intracellular parasites such as those of the Eimeria genus (Dalloul and Lillehoj, 2005). The use of recombinant proteins for assessing the ability to stimulate protective immunity against avian coccidiosis has been studied previously (Dunn et al., 1995; de Venevelles et al., 2004; Ding et al., 2005; Liu et al., 2009; Song et al., 2013), with the aim of producing an alternative to the anticoccidial agents used in poultry feed.

The $h s p 70$ gene encodes an internal protein (Liu et al., 2009) with a molecular mass of approximately $70 \mathrm{kDa}$ (del Cacho et al., 2001); it is found on the sporozoites of Eimeria spp and plays an important role in the formation of sporocysts and sporozoites during sporulation, and the formation of the synaptonemal complex during meiosis (Laurent et al., 1994; Del

Genetics and Molecular Research 16 (1): gmr16018964 
Cacho et al., 2008). Furthermore, HSP70 is essential for host cell invasion, working with HSP90 to facilitate the stabilization of transmembrane proteins in cell adhesion (Péroval et al., 2006).

Analysis of the soluble and insoluble fractions revealed that rHSP70 appeared only in the insoluble fraction, as expected, and that most of the contaminant insoluble proteins were removed from the supernatant, representing the flow-through of insoluble proteins not bound to the nickel in the column.

We selected a 489-bp PCR amplicon of the $h s p 70$ gene in the initial stages of this study. However, a 1092-bp fragment was observed. The difference in size was due to the presence of introns. Therefore, the sequence was deposited in GenBank (KT364872) with the appropriate annotations for introns and exons. Other researchers have evaluated the HSP70 proteins of Eimeria spp in terms of sequencing, expression, and antigenic/immunological characterization (Laurent et al., 1994; Bumstead et al., 1995; Dunn et al., 1995; Brown et al., 2000; del Cacho et al., 2001; de Venevelles et al., 2004; del Cacho et al., 2005; Del Cacho et al., 2008; Liu et al., 2009; Zhang et al., 2012). Studies on HSP70 from other species of microorganisms also suggest it has immunogenic potential, as observed by Li et al. (2011) when evaluating the HSP70 of Mycoplasma ovipneumoniae in sheep.

In conclusion, we obtained a high yield of insoluble recombinant protein by cloning, expressing, and purifying E. tenella rHSP70. However, additional studies are needed to assess and characterize its immunogenicity for vaccine protocols.

\section{Conflicts of interest}

The authors declare no conflict of interest.

\section{ACKNOWLEDGMENTS}

Research supported by Conselho Nacional de Desenvolvimento Científico e Tecnológico (CNPq; grant \#578721/2008-2) and Coordenação de Aperfeiçoamento de Pessoal de Nível Superior (CAPES \#AUXPE-1345/11). J.L. Garcia is the recipient of CNPq fellowships.

\section{REFERENCES}

Ahmad TA, El-Sayed BA and El-Sayed LH (2016). Development of immunization trials against Eimeria spp. Trials Vaccinol. 5: 38-47. http://dx.doi.org/10.1016/j.trivac.2016.02.001

Brown PJ, Billington KJ, Bumstead JM, Clark JD, et al. (2000). A microneme protein from Eimeria tenella with homology to the Apple domains of coagulation factor XI and plasma pre-kallikrein. Mol. Biochem. Parasitol. 107: 91-102. http://dx.doi.org/10.1016/S0166-6851(00)00179-1

Bumstead JM, Dunn PP and Tomley FM (1995). Nitrocellulose immunoblotting for identification and molecular gene cloning of Eimeria maxima antigens that stimulate lymphocyte proliferation. Clin. Diagn. Lab. Immunol. 2: 524-530.

Dalloul RA and Lillehoj HS (2005). Recent advances in immunomodulation and vaccination strategies against coccidiosis. Avian Dis. 49: 1-8. http://dx.doi.org/10.1637/7306-11150R

de Venevelles P, Chich JF, Faigle W, Loew D, et al. (2004). Towards a reference map of Eimeria tenella sporozoite proteins by two-dimensional electrophoresis and mass spectrometry. Int. J. Parasitol. 34: 1321-1331. http://dx.doi. org/10.1016/j.ijpara.2004.08.002

del Cacho E, Gallego M, Pereboom D, López-Bernad F, et al. (2001). Eimeria tenella: hsp70 expression during sporogony. J. Parasitol. 87: 946-950. http://dx.doi.org/10.2307/3285212

Genetics and Molecular Research 16 (1): gmr16018964 
del Cacho E, Gallego M, López-Bernad F, Quílez J, et al. (2005). Differences in Hsp70 expression in the sporozoites of the original strain and precocious lines of Eimeria tenella. J. Parasitol. 91: 1127-1131. http://dx.doi.org/10.1645/ GE-3464.1

Del Cacho E, Gallego M, Pages M, Monteagudo L, et al. (2008). HSP70 is part of the synaptonemal complex in Eimeria tenella. Parasitol. Int. 57: 454-459. http://dx.doi.org/10.1016/j.parint.2008.05.005

Ding X, Lillehoj HS, Dalloul RA, Min W, et al. (2005). In ovo vaccination with the Eimeria tenella EtMIC2 gene induces protective immunity against coccidiosis. Vaccine 23: 3733-3740. http://dx.doi.org/10.1016/j.vaccine.2005.01.144

Dunn PP, Billington K, Bumstead JM and Tomley FM (1995). Isolation and sequences of cDNA clones for cytosolic and organellar hsp70 species in Eimeria spp. Mol. Biochem. Parasitol. 70: 211-215. http://dx.doi.org/10.1016/01666851(95)00014-R

Garcia JL, Guimarães JdaS, Jr., Headley SA, Bogado AL, et al. (2008). Eimeria tenella: utilization of a nasal vaccine with sporozoite antigens incorporated into Iscom as protection for broiler breeders against a homologous challenge. Exp. Parasitol. 120: 185-190. http://dx.doi.org/10.1016/j.exppara.2008.07.007

Igarashi M, Zulpo DL, Cunha IA, Barros LD, et al. (2010). Toxoplasma gondii: humoral and cellular immune response of $\mathrm{BALB} / \mathrm{c}$ mice immunized via intranasal route with rTgROP2. Rev. Bras. Parasitol. Vet. 19: 210-216. http://dx.doi. org/10.1590/S1984-29612010000400004

Jang SI, Lillehoj HS, Lee SH, Lee KW, et al. (2011). Mucosal immunity against Eimeria acervulina infection in broiler chickens following oral immunization with profilin in Montanide ${ }^{\mathrm{TM}}$ adjuvants. Exp. Parasitol. 129: 36-41. http:// dx.doi.org/10.1016/j.exppara.2011.05.021

Kyte J and Doolittle RF (1982). A simple method for displaying the hydropathic character of a protein. J. Mol. Biol. 157: 105-132. http://dx.doi.org/10.1016/0022-2836(82)90515-0

Laurent F, Bourdieu C, Yvoré P and Péry P (1994). Cloning and expression of cDNA encoding an Eimeria acervulina 70 $\mathrm{kDa}$ sporozoite protein which is related to the $70 \mathrm{kDa}$ heat-shock protein family. Mol. Biochem. Parasitol. 66: 349 352. http://dx.doi.org/10.1016/0166-6851(94)90161-9

Li M, Ma CJ, Liu XM, Zhao D, et al. (2011). Molecular cloning of HSP70 in Mycoplasma ovipneumoniae and comparison with that of other mycoplasmas. Genet. Mol. Res. 10: 834-848. http://dx.doi.org/10.4238/vol10-2gmr1193

Lillehoj HS, Ding X, Quiroz MA, Bevensee E, et al. (2005). Resistance to intestinal coccidiosis following DNA immunization with the cloned 3-1E Eimeria gene plus IL-2, IL-15, and IFN-gamma. Avian Dis. 49: 112-117. http:// dx.doi.org/10.1637/7249-073004R

Liu L, Xu L, Yan F, Yan R, et al. (2009). Immunoproteomic analysis of the second-generation merozoite proteins of Eimeria tenella. Vet. Parasitol. 164: 173-182. http://dx.doi.org/10.1016/j.vetpar.2009.05.016

Ma D, Ma C, Pan L, Li G, et al. (2011). Vaccination of chickens with DNA vaccine encoding Eimeria acervulina 3-1E and chicken IL-15 offers protection against homologous challenge. Exp. Parasitol. 127: 208-214. http://dx.doi. org/10.1016/j.exppara.2010.07.015

Meunier M, Chemaly M and Dory D (2016). DNA vaccination of poultry: The current status in 2015. Vaccine 34: 202211. http://dx.doi.org/10.1016/j.vaccine.2015.11.043

Mohamed RM, Aosai F, Chen M, Mun HS, et al. (2003). Induction of protective immunity by DNA vaccination with Toxoplasma gondii HSP70, HSP30 and SAG1 genes. Vaccine 21: 2852-2861. http://dx.doi.org/10.1016/S0264$\underline{410 X(03) 00157-9}$

Péroval M, Péry P and Labbé M (2006). The heat shock protein 90 of Eimeria tenella is essential for invasion of host cell and schizont growth. Int. J. Parasitol. 36: 1205-1215. http://dx.doi.org/10.1016/j.ijpara.2006.04.006

Shirley MW, Ivens A, Gruber A, Madeira AM, et al. (2004). The Eimeria genome projects: a sequence of events. Trends Parasitol. 20: 199-201. http://dx.doi.org/10.1016/j.pt.2004.02.005

Song H, Qiu B, Yan R, Xu L, et al. (2013). The protective efficacy of chimeric SO7/IL-2 DNA vaccine against coccidiosis in chickens. Res. Vet. Sci. 94: 562-567. http://dx.doi.org/10.1016/j.rvsc.2012.11.006

Thompson JD, Gibson TJ, Plewniak F, Jeanmougin F, et al. (1997). The CLUSTAL_X windows interface: flexible strategies for multiple sequence alignment aided by quality analysis tools. Nucleic Acids Res. 25: 4876-4882. http:// dx.doi.org/10.1093/nar/25.24.4876

Williams RB (2002). Fifty years of anticoccidial vaccines for poultry (1952-2002). Avian Dis. 46: 775-802. http://dx.doi. org/10.1637/0005-2086(2002)046[0775:FYOAVF]2.0.CO;2

Zhang L, Ma L, Liu R, Zhang Y, et al. (2012). Eimeria tenella heat shock protein 70 enhances protection of recombinant microneme protein MIC2 subunit antigen vaccination against E. tenella challenge. Vet. Parasitol. 188: 239-246. http://dx.doi.org/10.1016/j.vetpar.2012.03.025

Genetics and Molecular Research 16 (1): gmr16018964 